\title{
Constructing Productive Engagement: Pre-engagement Tools for Emerging Technologies
}

\author{
Haico te Kulve $\cdot$ Arie Rip
}

Received: 30 November 2007/Accepted: 11 July 2011/Published online: 6 September 2011

(C) The Author(s) 2011. This article is published with open access at Springerlink.com

\begin{abstract}
Engagement with stakeholders and civil society is increasingly important for new scientific and technological developments. Preparation of such engagements sets the stage for engagement activities and thus contributes to their outcomes. Preparation is a demanding task, particularly if the facilitating agent aims for timely engagement related to emerging technologies. Requirements for such preparation include understanding of the emerging science \& technology and its dynamics. Multi-level analysis and socio-technical scenarios are two complementary tools for constructing productive engagement. Examination of the emergence of nanotechnologies in the food packaging sector demonstrates how these tools work. In light of recent policy demands for responsible innovation, but also more generally, the role of organizers of engagement activities is one that deserves reflection insofar as it can extend beyond that of preparation and facilitation.
\end{abstract}

Keywords Engagement · Pre-engagement · Multi-level dynamics · Anticipatory co-ordination $\cdot$ Nanotechnology $\cdot$ Scenarios

\section{Introduction}

Interactions among promoters of new science and technology, other stakeholders, and civil society actors for the purpose of broadening decision and policy making

An earlier version of this paper was presented at the annual meeting of the Society for Social Studies of Science (4S) in Montreal, Quebec in October 2007.

H. te Kulve $(\bowtie) \cdot$ A. Rip

Department of Science, Technology, and Policy Studies, School of Management and Governance, University of Twente, PO Box 217, 7500 AE Enschede, The Netherlands

e-mail: h.tekulve@utwente.nl

A. Rip

e-mail: a.rip@utwente.nl 
processes have attracted considerable attention both inside and outside academia. Such engagement has been criticized for inadequate timing (Rogers-Hayden and Pidgeon 2007; Joly and Rip 2007). Engagement is often organized only after a particular issue has emerged, when it may be too late to make a difference. However, engagements in early stages of technology developments need to grapple with uncertainty or even ignorance about possible impacts of new technologies (Collingridge 1982). Whatever the timing of the engagement, it requires preengagement activities to help mitigate the dilemma between early engagement, which is full of unknowns, and late engagement, when socio-technical developments are already entrenched. A key point is that merely organizing and moderating stakeholder interactions is not enough. Engagements must be about substance, which requires preparation. This preparation-pre-engagement-is a challenge in its own right.

Pre-engagement activities include an organizational component such as inviting people and setting up a location. But they have to enable anticipation in a situation which is full of uncertainties: whether expectations for new technologies will materialize, how they might be integrated into value chains, which regulatory measures may obtain, and the nature of broader societal acceptance. To support such anticipation, analysis of ongoing societal and technological developments is necessary-drawing on science and technology studies and innovation studies. Also, some reduction of the complexity posed by uncertainties and ignorance is necessary to facilitate deliberations between stakeholders. A further point is then that reduction of complexity needs to be open-ended to take the fluidity of the situation into account and to avoid biases regarding (selection of) particular options. This is where socio-technical scenarios play an important role. ${ }^{1}$

Such pre-engagement activities will improve the quality of the actual engagement: interactions can be more productive. Participants will be supported in their reflection about future developments and their own role in it, and in their articulation of strategies; in other words, participants' reflexivity, will be enhanced. This sets the scene for better outcomes that are adapted to the nature of the situation and the timing of the engagement. While the challenge of intervening at a moment when it is still possible to modify the course of developments remains, it can be addressed concretely.

\section{Requirements for Pre-engagement}

A recent evaluation of nanotechnology engagement projects in the UK suggests that pre-engagements have an important role in early-stage engagement activities (Gavelin et al. 2007). In the UK, the idea of upstream, public engagement has been developed as a response to concern about timely engagement (Rogers-Hayden and Pidgeon 2007). Nanotechnologies, whose future shape and embedding in society

\footnotetext{
1 The first Yearbook of Nanotechnology in Society includes chapters that address such scenarios (Rip and Te Kulve 2008; Goorden et al. 2008). The argument given for the use of such scenarios in Rip (2008) includes the importance of connecting with perspectives of nanotechnology developers.
} 
(through the introduction and uptake of nanotechnology-enabled products in society) are quite uncertain and are an obvious target. The evaluation argued that the upstream engagement projects contributed to improved mutual understanding between scientists and members of the public. One criticism was the lack of clear links with nanotechnology policy and decision making processes. The report authors argued that this was related to the lack of a clear strategy of the UK government about what to do with public engagement activities and they offered several recommendations to overcome this problem, including more focus on purpose and outcomes of engagement activities and more involvement of decision-makers.

While the UK evaluation recommended requirements for public upstream engagement projects in order to improve their outcomes, it glossed over how to realize such requirements. The diagnosis was that the upstream projects were noncommittal exercises, and this was linked to a relatively low degree of structuring of engagements in terms of objectives, issues at stake, and involvement of actors with sufficient agency to make a difference. This highlights the role here for engagement agents, i.e. individuals and organizations orchestrating engagement activities, who are not immediate stakeholders or otherwise seen as impartial. Such engagement agents have to prepare and develop tools to do so, for instance when organizing Constructive Technology Assessment (CTA) workshops (Rip 2008; Rip and Te Kulve 2008). In general, a key point is the degree to which socio-technical developments have become articulated and are embedded in actors' activities, because this defines how much structuring of engagement activities is embedded in the situation already and how much must be constructed by engagement agents.

A further point is that timely engagement with emerging technologies, and their development and embedding in society, includes an action perspective for the engagement agents. For CTA, this has been formulated as CTA agents having a second-order goal: not the first-order goal of realizing or criticizing technology $\mathrm{X}$ (which is what they enable actors to do), but to enhance actors' reflexivity within the overall development of the technology (Schot and Rip 1997). Thus, processes of technology development and their embedding in society will become more reflexive.

This brief discussion of engagements and engagement agents prepares the ground for an outline of requirements for pre-engagement activities, i.e. "timely" analysis and structuring of actor's interactions.

First, understanding is required of the emerging science and technology and its dynamics, especially the various expectations and emerging/partial path dependencies which can be seen as 'endogenous futures' (Rip and Te Kulve 2008). Tools to do this are by now available_-see for instance the work of Douglas Robinson and Tilo Propp (2008). Note that such tools are particularly suited for midstream engagement (Fisher et al. 2006; Joly and Rip 2007), where some articulation has occurred already, but where developments are still open-ended and relatively malleable.

A second requirement is to assess actor's propensities to anticipate future societal embedding of new technologies (Deuten et al. 1997), and to coordinate their activities with those of other actors. There are clear differences, for example between Monsanto's refusal to interact with civil society groups about their 
genetically modified product development, and DuPont's willingness to cooperate with Environmental Defense to formulate a risk framework for nanomaterials. There are also differences in willingness to engage in anticipatory coordination. The semiconductor sector has a long-standing and authoritative tradition of regularly preparing an International Technology Roadmap for Semi-Conductors and is now making attempts to address new developments "beyond Moore's Law." ${ }^{2}$ In contrast, in the food and food packaging sector (discussed in some detail below), the opportunities and risks of emerging nanotechnologies are only incidentally taken up in consultation and coordination activities. It is thus clear that, although important, more is involved than willingness to enter into a dialogue (or multilogue) with other actors. The propensities to be assessed play a role in the further development and societal embedding of the technologies.

A third set of requirements concern how to select and locate actors, which is linked to the envisaged orchestration of interactions during the engagement. Participants can be chosen on the basis of demographic or professional characteristics, but also on the basis of their role-or for that matter, lack of a role-in the socio-technical dynamics. For example in food packaging, retailers have a powerful position in the market introduction of new products, so they must be included in engagement activities.

Fourthly, broader developments that may not always be visible to the various actors have to be taken into account. Consider the role of parties which are not directly involved in technological developments and their embedding in society, but which may still exert influence. Insurance companies are a good example: they are driven by financial interests, but their requirements for offering insurance coverage can include requirements on the technology. And they can become proactive, as when Swiss Re in 2004 issued its report on risks of nano-particles, which transformed an earlier contested issue into a legitimate concern (Swiss Re 2004). Another example is how articulation and integration of ethical, legal and social implications (ELSI) of technological development trajectories (first introduced as part of the Human Genome Project but since the early 1990s, have become a separate funding line in the budget and not really integrated into the Human Genome Project itself), is becoming a real concern, especially for nanotechnology. Incipient institutionalization is visible in articulation of codes of conduct fostering responsible innovation, and the engagement of big firms in dialogues with stakeholders.

Nanotechnologies for food packaging applications illustrate how these requirements can be addressed in a particular case. The first step, however, is general: the importance of analysing multi-level dynamics, where actors and their practices interact with sectoral dynamics including evolving industry structures, and how these dynamics co-evolve with more global developments. By now, this type of analysis is well-established in science, technology and innovation studies (Geels

\footnotetext{
${ }^{2}$ See for example the announcement on their website (http://www.itrs.net/): "The International Roadmap Committee has released a new white paper on the topic "More than Moore" and roadmapping. This white paper proposes a methodology to help the ITRS community identify those More than Moore (MtM) technologies for which a roadmapping effort is feasible and desirable. This document is now available for download" (visited 30 July 2011).
} 
2002; Nelson 1995), and it can be extended to cover societal embedding (Robinson and Propp 2008). Based on this, socio-technical scenarios can also be constructed.

\section{Multi-Level Dynamics in Societal Embedding Processes}

Engagements aim to gather a heterogeneous set of actors with different sociocognitive perspectives (as Garud and Ahlstrom 1997 emphasized) and to elicit, and deliberate on, views and activities related to developments in a particular domain of science and technology. The broader goal of such engagements is to improve processes of societal embedding and their outcomes. Thus, some anticipatory coordination of current and future activities is in order, and pre-engagement should stimulate and support that. To do so, we take a closer look at what we call alignment between actors and activities. ${ }^{3}$

In their analysis of societal embedding and product creation management Deuten et al. (1997) first characterize societal embedment of new technologies by three dimensions: 'integration' in relevant industries and markets, 'admissibility' according to regulation, and 'some degree of acceptance' by the public (Deuten et al. 1997, p. 131). Then they point out that there is a structural problem in the development of alignments related to new technologies and products, which derives from the way technology developers and managers adopt a concentric view of their environment (cf. Swiss Re 2004): first comes the business environment, then regulation environment, and lastly, wider society. These environments are then addressed sequentially rather than simultaneously, so alignments with the wider society are developed at a late stage. When problems, for example with public acceptance, become manifest, they will be difficult to resolve. Deuten et al. (1997) make the general claim that ongoing anticipation of societal embedding is required in addition to product development, whether or not such anticipation includes public engagement.

Societal embedding of technologies requires alignment work anyhow. The outcomes of such alignment processes may be unintended. Alignment refers to the eventual entanglement of actors and activities so that there are mutual dependencies; they cannot move completely independently. Alignment also implies that there is some mutual accommodation, like parts fitting together, creating a configuration that works-which de facto steers actors' activities and interactions in certain directions. Anticipatory co-ordination can now be positioned as the development of alignments between levels of activities that take into account the prospective development and introduction of new technologies.

Alignment processes across different levels of activities are visible in the world of nanotechnologies. Entrepreneurs mobilize resources for novel research and

\footnotetext{
3 Joan Fujimura's (1987) analysis of how researchers construct 'do-able problems' through alignment work (termed articulation tasks) is interesting because it takes the multi-level nature of the situation into account and conceptualizes alignment as alignment across levels. Her approach is concentric, however, focusing on the research actor making research doable by aligning the experiment, lab, and wider social world.
} 
product development activities and draw upon expectations about wonderful benefits in order to legitimize such investments. When entrepreneurs mobilize allies and financial resources, they create novel linkages between envisioned outcomes of research activities as well as expected contributions to societal issues or problems. ${ }^{4}$ Entrepreneurs may themselves be constrained by linkages they created during their mobilization activities. In their study of the development of a nanotechnology research cluster Mangematin et al. (2005) argued that entrepreneurs create momentum, and when achieved, it carries them on.

Alignment across levels is of interest because it introduces a particular form of stabilization: if actors appear to move in other directions and might actually be able to do so on their own level, they will now be constrained by the links to another level with its own dynamics. A simple example would be research practices constrained by rules of funding agencies and programmes to be conservative and/or follow certain directions. In other words, activities at a particular level are shaped by dynamics at that level, but also through alignments with, and thus the dynamics at, other levels.

Actors who can work at more than one level are important for eventual alignment. They act as connectors and can become 'linking pins' between levels of activities. Venues for inter-level interaction which will be visible in the food packaging case study below, are forums and in general, spaces in which actors active at different levels can interact and try out new linkages and alignments. Dedicated alignment actors include 'promise champions' who circulate expectations and build agendas (Van Lente and Rip 1998); network builders who enrol new actors (Elzen et al. 1996); and institutional entrepreneurs who establish new rules such as standards (Garud et al. 2002), meanings, and practices related to new technologies (Munir and Philips 2005). These entrepreneurial activities can serve as an empirical entrance point to mapping multi-level dynamics in the case of nanotechnology and food packaging.

Entrepreneurial activities can also provide the starting point for constructing socio-technical scenarios, the second pre-engagement tool. Scenarios fulfil a dual role. Firstly, they are useful for facilitating deliberations between stakeholders and to assess future changes in multi-level dynamics and the possible evolution of attempts at anticipatory co-ordination (not as a mere extrapolation of trends, but in terms of shifts and branching of developments starting with the present situation and its dynamics) (Rip 1995). Scenarios can highlight alternative futures as such, but for pre-engagement it is more important to explore what may happen when actors at one level, or across levels, get involved in de facto alignment activities.

Secondly, scenarios of future developments show possible worlds. Thus, they can be used to identify actors and dynamics that were not very visible in the mapping exercise. They also highlight what might be at stake in a particular domain and what are possible societal and ethical dilemmas. During engagement activities, the scenarios themselves can be offered as playgrounds where anticipatory coordination and alignment can be explored virtually by the participants.

\footnotetext{
4 Abernathy and Clark (1985) similarly emphasize that the advent of an innovation involves the continuation or obsolescence of earlier technological capabilities and customer linkages, and the need to refine existing or create new capabilities and linkages.
} 


\section{Nanotechnologies for Food Packaging: Three Scenarios}

An interesting case for the approach described above is the food sector, where high expectations regarding the application of nanotechnologies abound, but firms are concerned that such applications might backfire. Within the sector, food packaging is expected to take the lead in the application of nanotechnologies. At first sight, the use of nanotechnology in packaging applications appears less controversial than food ingredients designed and developed with nanotechnologies. However, concerns are already voiced regarding issues such as the environmental impacts of silver nanoparticles and the reliability of sensors indicating food spoilage.

The mapping of multi-level dynamics below draws upon European and North American sources and does not focus on possible regional differences. A general picture of the uptake of nanotechnologies in the food packaging sector is sufficient to demonstrate this approach. For specific engagement exercises more contextualization is necessary to account for regional differences and local circumstances.

Packaging is an omnipresent technology where a wide variety of materials are used in different forms and shapes from basic material such as wood, plastics, textiles, paper and paperboard as well as additional materials such as inks and glues (Sandgren 1996). The value of the production of packaging materials alone is estimated at 400 billion euros: food packaging itself accounts for 35\% (Pira International 2003). The food packaging sector is an intersection of food and packaging product value chains (Cottica 1994), with several additional actors including research institutes, regulatory agencies and NGOs (see also the work of Kees Sonneveld (2000)).

There is ongoing research on the development of nanotechnologies for packaging applications. For example, nanocomposites of kaolinite clays (Lagarón et al. 2005) and bio-nanocomposites (Sorrentino et al. 2007) to improve barrier properties, antimicrobial properties of nanosilver particles (Joerger 2007), sensors that can detect food spoilage or existence of pathogens (ElAmin 2006a; Pehanich 2006) and nano barcodes to authenticate sources of products (Roberts 2007). A few nano enabled food packaging technologies are being introduced on the market such as nanocomposites for plastic packaging (Manolis Sherman 2004) and food containers containing antimicrobial nano particles (Anonymous 2006). Researchers in the field believe there are many unexplored possibilities.

\section{Mapping Multi-Level Dynamics}

\section{Development of Nano Food Packaging Discourse}

The dynamics of expectations are an important aspect of emerging technologies (Borup et al. 2006) and are visible in articulations of the potential benefits and adoption of new technologies. In the case of food packaging, industry observers expect that "nanotechnology will change 25 per cent of the food packaging market... in the decade to follow." (Reynolds 2007) Nanotechnologies are expected to contribute to the preservation of food through enhanced packaging technologies. 
Roadmaps are a way to articulate and specify expectations, and are often used. The Dutch quasi branch association for micro- and nanotechnologies, MinacNed initiated a roadmap (Prisma \& Partners and MinacNed 2006) which served as a forum that facilitated the development of linkages through the articulation of necessary alignments between a macro-level discourse on benefits of future technologies and micro-level research activities. The drawing up of such a roadmap was also an attempt to mobilize resources and co-ordinate future activities: the presentation of the roadmap at a seminar was accompanied by a call from the organizers to form consortia to implement the roadmap.

A second aspect of the discourse derives from the general phenomenon that the development of new technologies is subject to proponent-opponent controversies (Rip and Talma 1998) and expectations of future benefits are accompanied by expectations of possible risks. Actually, such controversies are now expected by proponents and can lead to fear of possible fears, in some cases even 'nanophobia phobia' (Rip 2006). In the case of nanotechnologies for food applications: "The food industry is hooked on nano-tech's promises, but it is also very nervous" (Renton 2006). Indeed, some concerns have been voiced, for example by Friends of the Earth, about the use of nanosilver particles for antimicrobial packaging (Miller and Senjen 2008). ${ }^{5}$ The MinacNed roadmap (Prisma \& Partners and MinacNed 2006) and food packaging experts interviewed within the Nanologue project (Nanologue 2006) also voiced scepticism regarding the profitability of investments in nanotechnologies for food packaging related to the costs of new nanomaterials.

Research and the development of nanotechnologies does not appear to be a high priority on the food packaging sector's agenda. Early attempts by institutional entrepreneurs to promote the combination of nanotechnologies and food packaging such as Kraft who initiated the Nanotek Consortium in 2000, have moved to the background. ${ }^{6}$ Kraft has reduced its visible involvement with nanotechnologies through relabeling the consortium and its replacement by a new sponsor, Philip Morris USA (Feder 2006). Sustainability is the buzzword now in general packaging conferences such as the Packaging Summit Europe 2007 and Intertech-Pira's Sustainability in Packaging 2007. Consortia such as Sustainpack have been formed that focus on the sustainability aspects of new packaging technologies. They articulate expectations of future nano enabled packaging technologies which reduce packaging waste and improve useful packaging properties (ElAmin 2007; Nanowerk News 2007). Thus, if research and development in nanotechnology and product development are to be stimulated, it will need to be through this detour, rather than through dedicated alignment.

\footnotetext{
5 The concerns of Friends of the Earth are part of a broader controversy on the use of nanosilver particles in consumer products. For instance the use of nanosilver in washing machines and the decision of the US Environmental Protection Agency to limit regulation of nanosilver particles to washing machines have stirred debate (see also the work of Miller and Senjen 2008).

${ }^{6}$ Over time, institutional entrepreneurship initiatives in the food packaging sector have shifted in focus, emphasizing themes such as risks and responsible innovation rather than the promotion of nanotechnology research and development (Te Kulve 2010).
} 


\section{Development of Rules and Regulations}

Rules and regulations are important for development and uptake of new packaging technologies. In addition to explicit, formal regulation there is also de facto regulation on the level of the sector, as when retailers stipulate requirements (Sonneveld 2000). At this moment, specific regulation of nanotechnologies in food packaging is still in an early phase (Chau et al. 2007) and opinions differ regarding whether existing regulation is sufficient (Cole and Bergeson 2006; ElAmin 2006b). One of the attempts to bridge the gap was the launch of a voluntary reporting scheme by the British government (ElAmin 2006c). Interviews with researchers and companies as part of the Nanologue project pointed out that large retail chains play a decisive role. They are seen to "determine the diffusion of [nanotechnology]based applications for food packaging on the market" (Nanologue 2006, p. 25). Thus, in food packaging, there is a waiting game: regulators wait for firms to introduce nanotechnology-enabled products and firms wait for regulators to clarify regulations for nanotechnologies before they allocate resources to research and product development activities.

\section{Development of Socio-Technical Networks}

In food packaging, co-ordination of actors' interests in product development activities is a challenge as there is no single end user. Brand owners, retailers, distributors, consumers, waste managers may all set different requirements to packaging technologies.

The development of collaborations between actors at different locations, and hence novel linkages between levels, is made difficult by the fragmentation of the sector and by competition. With the exception of paper and cardboard based packaging technologies, food packaging has a relatively low degree of vertical integration and downstream signals may not always reach upstream players (Pira International 2003). Moreover, the development of nano food packaging "requires collaboration between the different organizations involved, which is somewhat of a new concept for an industry that is highly competitive and consequently has the tendency to be very secretive" (Holland 2007). Thus, because of the segmented structure of the food packaging sector, both the propensity of actors to invest in anticipatory co-ordination and the emergence of actors that are willing to act as connectors, will be low. Collaboration in the case of nanotechnologies is even more challenging because nanotechnologies add an additional domain of knowledge and skills to the development and production of packaging technologies (Prisma \& Partners and MinacNed 2006).

This brief mapping demonstrates the first pre-engagement tool. The mapping shows the challenges for entrepreneurs and platforms and forums when they attempt to develop new linkages between activities. The mapping provides the preengagement agent with a baseline and insight in dynamics from which scenarios can be developed. 
Three Scenarios of Future Developments in Anticipatory Co-ordination

The starting point for the scenarios is the current situation in which research on nano food packaging applications occurs in a few places, predominantly research institutes and big firms. Articulation of regulatory aspects as well as possible benefits and risks for both firms and consumers is still relatively underdeveloped. Based on an overall diagnosis of how multi-level alignment occurs, we distinguish three possibilities that can be developed into three separate scenarios: (1) no crosslevel activities nor attempts at anticipatory coordination; (2) top-down activities by government, reducing strategic uncertainty by introducing some regulation; (3) midlevel activities of entrepreneurs animating platforms. ${ }^{7}$ These scenarios show that the development and subsequent embedding of nanotechnology in food packaging increases from the first to the third. Of course, in the real world, all three dynamics might occur to some extent and create a patchwork outcome. The scenarios should not be seen as mutually exclusive alternatives.

Scenario 1: "Little Nano" (limited development of nano food packaging). Research institutes recognize the apparent impasse in the development of nano food packaging, but are not pro-active in trying to change this situation as they do not consider it one of their tasks. Individual researchers as well as institutes anticipate that they will increasingly be held accountable for valorisation, given the dissatisfaction among policy makers and industrialists about the present limited short term valorisation of research. ${ }^{8}$ They attempt to meet such requirements by shifting their research, and do not focus on the often highly uncertain long term promises of nanotechnologies, especially for active and intelligent packaging purposes. By reorienting research objectives this way, fewer resources are left to allocate to investigation of more long-term nano food packaging. Big promises of nano-enabled food packaging fade, and discussion of its possible impacts seem irrelevant. Firms appear to be content with this situation.

Scenario 2: "Regulation Helps" (Regulation Supports Development of Nano Food Packaging).

Societal debates on the desirability and risks of nanoparticles continue, relatively independent of ongoing research and development activities of nano-technologies for food packaging and attempts to mobilize resources. Food regulatory agencies are under pressure from policy makers and NGOs and initiate actions to assess and regulate nano-related health, environmental and safety risks. Existence of regulatory schemes is expected to influence consumer (and thus retailer) confidence, which lowers barriers to develop nano food packaging including the effort to meet regulatory requirements. For Small and Medium Enterprises (SMEs) and start ups, regulation is an additional burden, however, and because of their narrow product portfolio they are more vulnerable to an eventual controversy over risks and sideeffects. The big firms welcome their new competitive advantage, and proceedcautiously_with the development of nano food packaging products.

\footnotetext{
7 These scenarios have been previously published (Rip and Te Kulve 2008). Since then they have been developed further in preparation for a scenario workshop.

${ }^{8}$ See also Bjornstad and Wolfe (this issue, 2011).
} 
Scenario 3: "Thresholds are passed" (Broad Platforms Support Development of Nano Food Packaging).

Nanotechnology research entrepreneurs and some industrialists act as champions and linking entrepreneurs for nano food packaging and are able to create a few nano-platforms, despite residual reluctance because of concerns of risks and negative consumer perceptions. The big step is that some critical NGOs were persuaded to participate, with the argument that this allows them to make a difference in shaping future technologies. Firms expect that the participation of NGOs, taken as spokespersons for civil society, will help legitimize future products. Then, with additional involvement of, and support by, governmental agencies, a broad platform for the development and introduction of novel food packaging products is created which acts as a forum linking activities at different levels. Pharmaceutical companies, linked because of the blurring of boundaries between the food and health sector, join the platform when promising results of improved packaging properties become visible. The involvement of pharmaceutical packaging suppliers adds to the momentum of the development of novel nano enabled packaging materials by creating economies of scale.

These scenarios have been reduced to their outlines, which is sufficient to indicate the approach. To prepare for a concrete engagement activity, more detail is necessary, including reference to actual actors and activities. Such detailed scenarios have been made for other cases, and used in engagement workshops. ${ }^{9}$ The detailed versions of the three scenarios for nano food packaging were used in an engagement workshop in early 2009 (Te Kulve 2011).

\section{Discussion}

The case of food packaging demonstrates how engagements can be prepared for through multi-level analysis and scenarios. Multi-level mapping adds to the understanding of dynamics in the domain such as how dependencies between activities at different levels are shaped by rules of the game in the food packaging sector, but also by expectations of new nano enabled applications and attention for sustainability issues of packaging. Through mapping ongoing activities an overview of (emerging) networks attempting to co-ordinate development of nano-enabled packaging is created. More importantly, dynamics that enable and constrain such attempts at co-ordination can be mapped. This mapping is employed to select and position participants and orchestrate interactions in a workshop. It is important to select participants from different positions in the food packaging chain as well as from different levels of activities, in this case material suppliers, brand owners, research institutes, regulators, NGOs and especially retailers who are expected to act as gatekeepers. In addition, one can identify presently invisible actors, and that is where detailed scenarios play a role, because they suggest actors who might get

\footnotetext{
${ }^{9}$ See for instance engagement workshops including scenarios in technology assessment projects in Nanoned (Rip and Te Kulve 2008; Rip 2008), in NanoSoc (Goorden et al. 2008), NanoBioRaise (Godman and Hansson 2007) and in a project on genomics (Van Rijswoud et al. 2008).
} 
entangled and make a difference. The trend towards convergence of food and health is a case in point highlighted in scenario 3 through the involvement of pharmaceutical packaging suppliers. In addition the scenarios can be used to explore when broader societal aspects are likely to be articulated. In the case of food packaging we speculated that broader issues are more likely to be articulated when a broad platform is constructed. An overview of how the case study fulfills preengagement requirements is given in Table 1.

The scenarios will also function as support for deliberations, making the discussion more concrete. In such discussions the scenarios may be modified so that actors recognize themselves and the issues at stake for them-and others. A next step in such a workshop would be to collectively design linkages between various levels of activities. The workshop then becomes a temporary forum, a space in which prospective alignments can be explored and tried out. The composition of the workshop participants is then an important aspect, but also the positioning of the workshop, for example in relation to an existing network or branch organisation. And of course, whether there is something at stake in the domain, already visible for most of the participants, or recognized by them when following the scenarios and/or listening to the contributions in the workshop.

Engagement activities can be organized with different goals, depending on actors' perceptions of what is at stake. Governmental agencies and firms may organize engagements in the context of roadmapping which is focused on emerging technological paths rather than their embedding in society. Such roadmapping exercises benefit from adding multi-level analysis and scenarios as this broadens anticipation through taking explicitly into account what might happen during societal embedding of new technologies.

Table 1 Pre-engagement requirements in the case of food packaging

\begin{tabular}{ll}
\hline Pre-engagement requirements & Items considered in the case of food packaging \\
\hline $\begin{array}{l}\text { Understanding of socio-technical } \\
\text { dynamics in the domain }\end{array}$ & $\begin{array}{c}\text { Focus on development of immediately useful technologies such } \\
\text { as nanocomposites } \\
\text { Expectations of beneficial packaging properties, but also of } \\
\text { unprofitability and public backlashes } \\
\text { Nanotechnologies not a high priority on food packaging sector's } \\
\text { agenda; sustainability is referred to as a top priority } \\
\text { Waiting games } \\
\text { Estimation of actors' propensity for } \\
\text { Emerging consortia and networks } \\
\text { Anticipation of customers' preference for sustainable } \\
\text { packaging, cf. Sustainpack program } \\
\text { Retailers as gatekeepers } \\
\text { Importance of co-operation across the chain } \\
\text { Linkages between food and health sector: involvement of } \\
\text { pharmaceutical packaging suppliers } \\
\text { Assessment of broader dynamics }\end{array} \quad$ issues like reliability and social inequality \\
\hline
\end{tabular}


In constructive technology assessment (CTA), the general goal of engagement activities is to stimulate learning and to broaden decision and policy making processes. Engagement workshops are only one element in such processes, but evaluation of the workshops that have been held shows that some broadening and use of new insights occurs (Rip 2008). The goal of broadening is also visible in the responsibility of the engagement agent (the individual or organization orchestrating engagement activities). Our scenarios started with a situation where actors waited for each other to make the first step. The objective of an engagement project could then be seen to break through the waiting game, and this is definitely how promoters see it. Note that this should be done in a responsible way: by anticipating broader societal aspects as these products are introduced, such as environmental assessments of the disposal of packaging products and the reliability of improved shelf dates. The engagement workshop organizer thus has the task to make sure that such broadening is part of the scenarios.

It is clear that through engagement activities, the organizers may help to set things in motion or solidify ongoing developments-effects which themselves require critical examination, for example by considering tensions, conflicts, and what and who may be excluded.

Van Oudheusden (this issue, 2011) formulates a general call for more attention to power dynamics as engagement outcomes may reflect dominant positions and frames rather than stimulate genuine mutual engagement and learning. However, framing and dominance occur in any case, and in various ways, as group dynamics partly shape what actors say and are prepared to say during engagement events. In a reflexive vein, note that engagement agents, like the participants, are also embedded in a broader world of actions and interactions and are limited in what they can do. They need to negotiate with sponsors of the exercise about the substance of the activities, but also with participants. Engagement agents are one among many actors attempting to shape interactions and to create and orchestrate temporary forums for heterogeneous interactions. ${ }^{10}$

The organizers of an engagement exercise introduce further complexities as participants themselves. When organizers carefully analyze and position various ongoing dynamics in order to stimulate debate and reflexivity among participants, they might also include themselves and their strategies in the analysis and scenarios. In this way, the organizers reveal their agenda and strategies, which can, like the roles of the other actors, be discussed during the workshop.

Generally, scenarios can be used to 'play' with conflicts and tensions and see how they may work out. Tensions are linked to views and dependencies, and embedded in overall dynamics. Making them visible to participants will highlight a patchwork of power gradients-and in so doing van Oudheusden's concern can be addressed productively.

Clearly, engagement workshop organizers should not misrepresent their positions as 'mere facilitators' who are focused only on improving their analyses and approaches. The CTA goals of broadening and increasing reflexivity require facilitating, but with a further pro-active role. The previous point about facilitating

$\overline{10}$ One anonymous reviewer suggested this reflexive point. 
further developments, but in a responsible way, was an example. For engagement exercises about nanotechnology it connects with the present emphasis, at least in policy documents, on the responsible development of nanotechnology. This creates recognition of the importance of broadening, and in that sense makes life easier for CTA agents aiming to stimulate broadening and reflexivity. There is also an analytical responsibility, however, to position this trend of responsible innovation in ongoing dynamics. This may lead to the identification of relevant but up till now invisible actors who are then included as participants in the exercise. Such a proactive role of the organisers turns them into connectors themselves, and requires them to reflect on the socio-political agenda that is implicated in such action.

Acknowledgments The authors thank the Guest Editor, Erik Fisher, and two anonymous reviewers for their helpful comments and suggestions. This research is part of the Technology Assessment program of the R\&D Consortium NanoNed (www.nanoned.nl) in the Netherlands.

Open Access This article is distributed under the terms of the Creative Commons Attribution Noncommercial License which permits any noncommercial use, distribution, and reproduction in any medium, provided the original author(s) and source are credited.

\section{References}

Abernathy, W. J., \& Clark, K. B. (1985). Innovation: Mapping the winds of creative destruction. Research Policy, 14, 3-22.

Anonymous. (2006). Container uses nanoparticles to extend shelf life. http://www.foodproductiondaily. com/Packaging/Container-uses-nanoparticles-to-extend-shelf-life. Accessed 25-07-2011.

Bjornstad, D., \& Wolfe, A. (2011). Adding to the Mix: Integrating ELSI into a National Nanoscale Science and Technology Center. Science and Engineering Ethics, 17(3), (this issue).

Borup, M., Brown, N., Konrad, K., \& Lente, H. v. (2006). The sociology of expectations in science and technology. Technology Analysis \& Strategic Management, 18(3/4), 285-298.

Chau, C.-F., Wen, S.-H., \& Yen, G.-C. (2007). The development of regulations for food nanotechnology. Trends in Food Science \& Technology, 18, 269-280.

Cole, M. F., \& Bergeson, L. L. (2006). Regulatory report: FDA regulation of food packaging produced using nanotechnology. http://www.foodsafetymagazine.com/article.asp?id=942\&sub=sub1. Accessed 25-07-2011.

Collingridge, D. (1982). Social Control of Technology. London: Continuum International Publishing Group - Academi.

Cottica, A. (1994). The microeconomics of environmental innovation in the European packaging industry. In Fifth annual conference of the European association of environmental and resource economists, Dublin, 22-24 June 1994

Deuten, J. J., Rip, A., \& Jelsma, J. (1997). Societal embedding and product creation management. Technology Analysis \& Strategic Management, 9(2), 131-148.

ElAmin, A. (2006a). Nano ink indicates safety breach in food packaging. http://www.food productiondaily.com/Quality-Safety/Nano-ink-indicates-safety-breach-in-food-packaging. Accessed 24-7-2011.

ElAmin, A. (2006b). Nanotechnology regulatory oversight inadequate, study finds. http://www.fnbnews. com/article/detarchive. asp?articleid=19068\&sectionid=10. Accessed 25-07-2011.

ElAmin, A. (2006c). Voluntary nanotechnology reporting launched in UK. http://www.foodproduction daily.com/Supply-Chain/Voluntary-nanotechnology-reporting-launched-in-UK. Accessed 25-072011.

ElAmin, A. (2007). Nano project aims to reduce packaging waste. http://www.foodproductiondaily.com/ Packaging/Nano-project-aims-to-reduce-packaging-waste. Accessed 25-07-2011. 
Elzen, B., Enserink, B., \& Smit, W. A. (1996). Socio-technical networks: How a technology studies approach may help to solve problems related to technical change. Social Studies of Science, 26, 95-141.

Feder, B. J. (2006). Engineering food at level of molecules. The New York Times, October 10, p. N.A.

Fisher, E., Mahajan, R. L., \& Mitcham, C. (2006). Midstream modulation of technology: Governance from within. Bulletin of Science, Technology \& Society, 26(6), 485-496.

Fujimura, J. H. (1987). Constructing 'Do-Able' problems in cancer research: Articulating alignment. Social Studies of Science, 17(2), 257-293.

Garud, R., \& Ahlstrom, D. (1997). Technology assessment: A socio-cognitive perspective. Journal of Engineering and Technology Management, 14, 25-48.

Garud, R., Jain, S., \& Kumaraswamy, A. (2002). Institutional entrepreneurship in the sponsorship of common technological standards: The case of Sun Microsystems and Java. Academy of Management Journal, 45(1), 196-214.

Gavelin, K., Wilson, R., \& Doubleday, R. (2007). Democratic technologies? The final report of the nanotechnology engagement group (NEG). London: Involve.

Geels, F. W. (2002). Towards sociotechnical scenarios and reflexive anticipation: Using patterns and regularities in technology dynamics. In K. H. Sørensen \& R. Williams (Eds.), Shaping technology, guiding policy: Concepts, spaces and tools (pp. 359-385). Cheltenham: Edward Elgar.

Godman, M., \& Hansson, S. O. (2007). Public advice on the development of nanobiotechnology: Final report of four European convergence seminars. Stockholm: Royal Institute of Technology.

Goorden, L., Van Oudheusden, M., Evers, J., \& Deblonde, M. (2008). Nanotechnologies for tomorrow's society: A case for reflective action research in Flanders, Belgium. In E. Fisher, C. Selin, \& J. Wetmore (Eds.), The yearbook of nanotechnology in society, Volume 1: Presenting Futures (pp. 163-182). Berlin: Springer.

Holland, C. (2007). A small world with a big future. http://www.convertingtoday.co.uk/story.asp? sectioncode $=46 \&$ storycode $=48783$. Accessed 25-07-2011.

Joerger, R. D. (2007). Antimicrobial films for food applications: A quantitative analysis of their effectiveness. Packaging Technology and Science, 20, 231-273.

Joly, P.-B., \& Rip, A. (2007). A timely harvest. Nature, 450(7167), 174.

Lagarón, J. M., Cabedo, L., Cava, D., Feijoo, J. L., Gavara, R., \& Gimenez, E. (2005). Improving packaged food quality and safety. Part 2: Nanocomposites. Food Additives and Contaminants, 22(10), 994-998.

Mangematin, V., Rip, A., Delemarle, A., \& Robinson, D. K. R. (2005). The role of regional institutional entrepreneurs in the emergence of clusters in nanotechnologies. Working paper GAEL 2005-15. Grenoble: INRA.

Manolis Sherman, L. (2004). Chasing nanocomposites. Plastics Technology, 11, 56-61.

Miller, G., \& Senjen, R. (2008). Out of the laboratory and on to our plates: Nanotechnology in Food \& Agriculture. http://nano.foe.org.au/node/26. Accessed 25-07-2011.

Munir, K. A., \& Philips, N. (2005). The birth of the 'Kodak Moment': Institutional entrepreneurship and the adoption of new technologies. Organization Studies, 26(11), 1665-1687.

Nanologue. (2006). Nanologue opinions on the ethical, legal and social aspects of nanotechnologiesResults from a consultation with representatives from research, business and civil society. www.nanologue.net. Accessed 25-07-2011.

Nanowerk News (2007) Nanotechnology solutions for the packaging waste problem. http:// www.nanowerk.com/news/newsid=1852.php. Accessed 25-07-2011.

Nelson, R. R. (1995). Co-evolution of industry structure, technology and supporting institutions, and the making of comparative advantage. International Journal of the Economics of Business, 2(2), 171-184.

Pehanich, M. (2006). Small gains in processing, packaging. http://www.foodprocessing.com/articles/ 2006/228.html. Accessed 24-7-2011.

Pira International. (2003). Packaging in the 3rd Millennium: Competitiveness study for the packaging industry in the UK. http://www.packagingfedn.co.uk/images/reports/mainreport.pdf. Accessed 25-72011.

Prisma \& Partners, \& MinacNed. (2006). Roadmap microsystem- \& nanotechnology in food \& nutrition. Warnsveld: Prisma \& Partners, MinacNed.

Renton, A. (2006). Welcome to the world of nano foods. http://observer.guardian.co.uk/foodmonthly/ futureoffood/story/0,1971266,00.html. Accessed 25-07-2011. 
Reynolds, G. (2007) Future nanopackaging market worth billions, says study. http:// www.foodproductiondaily.com/news/ng.asp?id=76538. Accessed 25-07-2011.

Rip, A. (1995). Introduction of new technology: Making use of recent insights from sociology and economics of technology. Technology Analysis \& Strategic Management, 7(4), 417-431.

Rip, A. (2006). Folk theories of nanotechnologists. Science as Culture, 15(4), 349-365.

Rip, A. (2008). Nanoscience and nanotechnologies: Bridging gaps through constructive technology assessment. In G. Hirsch Hadorn, H. Hoffmann-Riem, S. Biber-Klemm, W. Grossenbacher-Mansuy, D. Joye, C. Pohl, et al. (Eds.), Handbook of transdisciplinary research (pp. 145-157). Berlin: Springer.

Rip, A., \& Talma, S. (1998). Antagonistic patterns and new technologies. In C. Disco \& B. J. Van der Meulen (Eds.), Getting new technologies together. Studies in making sociotechnical order (pp. 299-322). Berlin: Walter de Gruyter.

Rip, A., \& Te Kulve, H. (2008). Constructive technology assessment and socio-technical scenarios. In E. Fisher, C. Selin, \& J. M. Wetmore (Eds.), The yearbook of nanotechnology in society, Volume 1: Presenting futures (pp. 49-70). Berlin: Springer.

Roberts, R (2007) The role of nanotechnology in brand protection. http://www.packagingdigest.com/ article/340754-The_role_of_nanotechnology_in_brand_protection.php. Accessed 24-7-2011.

Robinson, D. K. R., \& Propp, T. (2008). Multi-path mapping for alignment strategies in emerging science and technologies. Technological Forecasting \& Social Change, 75, 517-538.

Rogers-Hayden, T., \& Pidgeon, N. (2007). Moving engagement "upstream"? Nanotechnologies and the royal society and royal academy of engineering's inquiry. Public Understanding of Science, 16, 345-364.

Sandgren, K. (1996). Material flow analysis for an industry-A case study in packaging. Nonrenewable Resources, 5(4), 235-247.

Schot, J., \& Rip, A. (1997). The past and future of constructive technology assessment. Technological Forecasting and Social Change, 54, 251-268.

Sonneveld, K. (2000). What drives (food) packaging innovation? Packaging Technology and Science, 13, 29-35.

Sorrentino, A., Gorrasi, G., \& Vittoria, V. (2007). Potential perspectives of bio-nanocomposites for food packaging applications. Trends in Food Science \& Technology, 18, 84-95.

Swiss Re. (2004). Small matters, many unknowns. Zürich: Swiss Reinsurance Company. Risk Perception Series.

Te Kulve, H. (2010). Emerging technologies and waiting games: Institutional entrepreneurs around nanotechnology in the food packaging sector. Science. Technology \& Innovation Studies, 6(1), 7-31.

Te Kulve, H. (2011). Anticipatory interventions and the co-evolution of nanotechnology and society. Dissertation, University of Twente, Enschede.

Van Lente, H., \& Rip, A. (1998). The rise of membrane technology: From rhetorics to social reality. Social Studies of Science, 28(2), 221-254.

Van Oudheusden, M. (2011). Questioning 'Participation': A critical appraisal of its conceptualization in a flemish participatory technology assessment. Science and Engineering Ethics, 17(3), (this issue).

Van Rijswoud, E., Stemerding, D., \& Swierstra, T. (2008). Genetica, genomics en gezondheidszorg: Een toekomstverkenning. Nijmegen: Centre for Society and Genomics. 